\title{
Properties of Sugarcane Fiber on the Strength of the Normal and Lightweight Concrete
}

\author{
Faisal Sheikh Khalid ${ }^{1, *}$,Herman Shah Herman ${ }^{1}$, and Nurul Bazilah Azmi ${ }^{1}$ \\ ${ }^{1}$ Faculty of Civil and Environment Engineering, Universiti Tun Hussein Onn Malaysia, 86400 Parit \\ Raja, Johor, Malaysia
}

\begin{abstract}
The usage of natural fiber in construction are widely used in building materials engineering. However, using sugarcane fiber waste material as a natural in construction is very precious, because it can increase crack control and ductility, brittle concrete. Furthermore, the usage of sugarcane in construction can reduce of environmental pollution.In this study, a mixture of sugarcane fiber to be used in normal grade concrete and lightweight concrete to determine whether there is an increase in the compressive and tensile strength of the concrete. The objective of this study was to determine the compressive and tensile strength between control concrete and concrete mix with sugarcane fiber. In addition, the optimal volume of sugarcane fiber in the concrete mixture where the percentage of sugarcane fiber used was $0.5 \%, 1.0 \%$ and $1.5 \%$. Compessive strength was tested on days 7 and 28 after curing test is carried out. Meanwhile, the tensile test, has been carried out to measure the tensile strength of sugarcane fiber relations in concrete mixes only at 28 day curing. Result of the testing showed that the optimum value containing admixtures of sugarcane is $0.5 \%$. This percentage get the value of compressive strength is nearest with concrete control and the value of tensile strength is higher than concrete control and also the timing of concrete to cracked getting slower. Therefore, the use of sugarcane fiber suitable for addition that do not exceed $0.5 \%$ of the concrete mixture.
\end{abstract}

\section{Introduction}

Concrete is made up of three main ingredients which is cement, aggregates and water. However, there were also other materials put into the concrete mix which is known as addictive to increase the strength of the concrete. Concrete has high compressive strength, corrosion and weathering effect are minimal. However, concrete has low tensile strength and easily can be crack due its characteristics which is brittle [1-3].

Nowadays, an increasing demand of concrete in the industries, researchers and scientist are developing alternate binders that are eco friendly and contribute towards waste management especially for agricultural waste such as sugarcane [2].There have many previous experimental have been conducted by using different volume of sugarcane bagasse. Baggase fiber is a by-product of sugarcane industry whose role is sugar, rum or

\footnotetext{
*Corresponding author: faisalsh@uthm.edu.my
} 
biofuel production. Sugarcane can help to improve the deficient tensile strength of concrete due to its limited tensile strength [2].

Sugarcane baggase have a little impact on the compressive strength of concrete $[4,5]$. The increasing of volume of concrete was reduced the compressive strength of the concrete. Olutoge [4] was claimed that baggase ash can increase the strength of concrete when used up to $10 \%$ cement and $30 \%$ fine aggregates replacement level . However, the flexural strength of concrete is decrease after certain percentage replacement of sugarcane baggase ash. The sugarcane baggase ash concrete had higher compressive strength compare to the concrete without sugarcane baggase ash [5]. The optimal level of sugarcane baggase ash content with $15 \%$ replacement. Many researchers show that sugarcane in high performance concrete as a partial replacement of Portland cement improved the rheological properties [6-9]. The method was implemented by grinding treatment that the ash received before its incorporation into the concrete mixtures. Cordeiro et al. [10] found an influence of sugarcane ash on the properties of concretes. Concrete containing sugarcane ash was produced using a vibratory grinding machine in a dry open circuit. Conventional and highperformance concretes were produced using $0 \%$ to $20 \%$ of these ashes as a cement replacement [11]. It can be concluded that the partial replacement of Portland cement sugarcane ash caused a slight increase in yield stress and a small reduction in plastic viscosity in both the conventional and high-strength concretes. The rheological evaluation of these causes is hardly to determine due to different particle sizes of the ingredients that form the mixture $[2,11]$.

This paper presents the results of research aimed to investigate the performance of sugaracane baggase as an addition material in normal and lightweight concrete. The utilization of sugarcane bagasse in concrete mix produced desired compressive strength, tensile strength and optimum sugarcane fiber in concrete.

\section{Methodology}

To achieve the objectives of this study, there are many approaches and methods that should be taken. Methods of work such as literature review, methods of mixing and testing in the laboratory is important to get a more accurate analysis results. The volume of sugarcane are $0.5 \%, 1.0 \%$ and $1.5 \%$ and use volume method for the design mix concrete for normal concrete that shown in Table 1 and lightweight concrete that shown in Table 2. The sugarcane fiber was used as shown in Fig. 1.

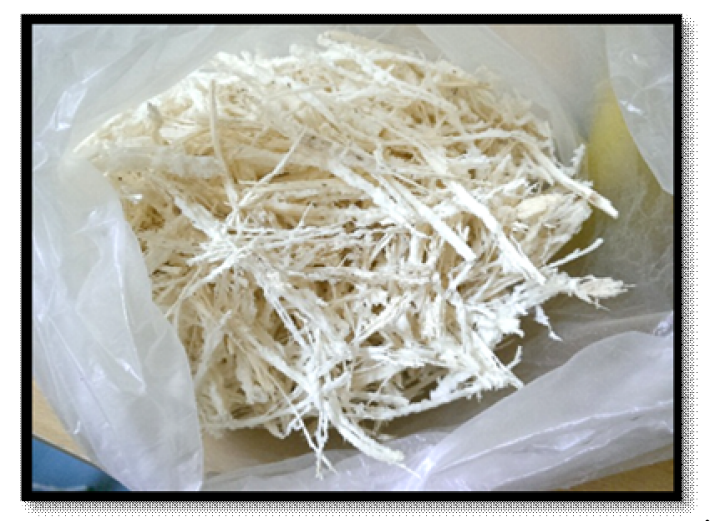

Fig. 1. Sugarcane fiber. 
The sugarcane bagasse will dry under the sun until completely dry for 7 days. Then the bagasse will cut into small relatively uniform strips with estimation $5 \mathrm{~cm}$ until $10 \mathrm{~cm}$. Fig. 2 shows the sugarcane bagasse dry under sun.

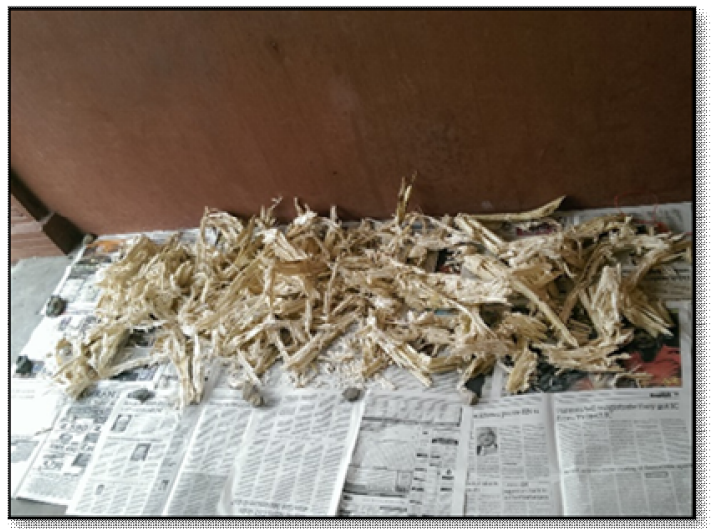

Fig. 2. Sugarcane was dried.

Furthermore, bagasse need to be treated first with Sodium Hydroxide $\mathrm{NaOH}$ Solution $50 \%$ dilute for 3 days as in Fig. 3. Purpose of the treatment is to remove the impurities and ensure the sugarcane withstand longer to use in concrete. Then, the treated sugarcane bagasse need to be dried under the sun to ensure it completely dried before adding into concrete mixture. The volume of sugarcane are $0.5 \%, 1.0 \%$ and $1.5 \%$ and use volume method for the design mix concrete for normal concrete that shown in Table 1 and lightweight concrete that shown in Table 2.
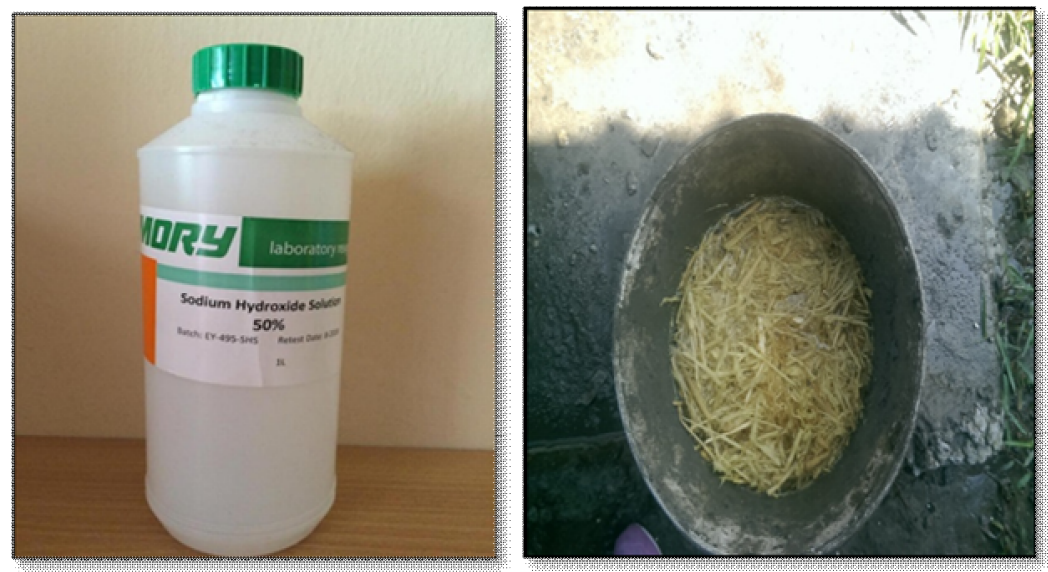

Fig. 3. Sugarcane that have treat in Sodium Hydroxide Solution.

The size of the cube used are $100 \mathrm{~mm} \times 100 \mathrm{~mm} \times 100 \mathrm{~mm}$ for the compression test for the tensile test size of cylinder used are $100 \mathrm{~mm}$ x $200 \mathrm{~mm}$. There are several tests conducted to achieve the objectives, which is compression and tensile tests of concrete that was done according to standard test $[12,13]$. The curing process was carried out for 7 and 
28 days in water at room temperature to let the concrete in the moist state as long as possible so that the hardening process happens in moderation in order to achieve maximum strength.

Table 1. Mix design of concrete for $1 \mathrm{~m}^{3}$.

\begin{tabular}{|c|c|c|c|}
\hline $\begin{array}{c}\text { Water } \\
\left(\mathrm{kg} / \mathrm{m}^{3}\right)\end{array}$ & Cement $\left(\mathrm{kg} / \mathrm{m}^{3}\right)$ & Sand $\left(\mathrm{kg} / \mathrm{m}^{3}\right)$ & $\begin{array}{c}\text { Coarse } \\
\text { aggregate } \\
\left(\mathrm{kg} / \mathrm{m}^{3}\right)\end{array}$ \\
\hline 209 & 300 & 980 & 805 \\
\hline
\end{tabular}

Table 2. Mix design of lightweight concrete for $1 \mathrm{~m}^{3}$.

\begin{tabular}{|c|c|c|c|}
\hline $\begin{array}{c}\text { Water } \\
\left(\mathrm{kg} / \mathrm{m}^{3}\right)\end{array}$ & Cement $\left(\mathrm{kg} / \mathrm{m}^{3}\right)$ & Sand $\left(\mathrm{kg} / \mathrm{m}^{3}\right)$ & Foam $\left(\mathrm{kg} / \mathrm{m}^{3}\right)$ \\
\hline 175 & 390 & 800 & 235 \\
\hline
\end{tabular}

\section{Results and discussion}

In this study, there are two types of tests carried out on 72 concrete samples which 32 samples are prepared for normal concrete and another 32 samples are prepared for lightweight concrete. Both of the sample was conducted compressive and tensile tests.

\subsection{Compressive strength of the concrete}

Fig. 4 shows that the control sample containing 0\% sugarcane recorded a reading of 18.00 MPa compressive strength. Samples containing $0.5 \%$ additive showed higher readings than the other percentage that is $14.8 \mathrm{MPa}$ for the curing 7 days. The sample containing $1.0 \%$ sugarcane representing $11.4 \mathrm{MPa}$. Sample containing 1.5\% sugarcane representing has lowest compressive strength for 7 days curing that is $9.6 \mathrm{MPa}$.

Meanwhile, compressive strength of concrete for curing period of 28 days after the cube was produced. Based on the figure, the control sample containing $0 \%$ sugarcane fiber recorded a reading of compressive strength is $23.80 \mathrm{MPa}$. For samples containing $0.5 \%$ additive showed compressive strength $21.30 \mathrm{MPa}$ meanwhile sample containing $1.0 \%$ recorded compressive strength $18.60 \mathrm{MPa}$. For sample $1.5 \%$ additive recorded the lowest compressive strength of concrete for samples 28 days that is $15.30 \mathrm{MPa}$. The lower compressive strength of fibrous mixtures might be attributed to the presence of fiber bundle (high percentage of fiber) during mixing $[14,15]$. These might attributed the voids due tothe addition of high percentage of fiber and the existence of a weak interfacial bonds among the fiber and concrete matrix $[9,10]$.

The lightweight concrete also was tested with compressive strength and result as shown in Fig. 4. The control sample that containing $0 \%$ of sugarcane bagasse was $3.74 \mathrm{MPa}$. Samples containing $0.5 \%$ bagasse obtained the highest value of compressive strength which was $6.50 \mathrm{MPa}$. Meanwhile, the value of compressive strength for samples containing $1.0 \%$ and $1.5 \%$ recorded slightly decline value compared to sample control and $0.5 \%$ which were 4.31 MPa and 1.54MPa after curing 7 days. 
Meanwhile, the result compressive strength of the concrete for 28 days, the control sample obtained value 7.10MPa. The sample containing $0.5 \%$ sugarcane bagasse recorded the highest value which is $10.30 \mathrm{MPa}$. However, the samples containing $1.5 \%$ sugarcane bagasse showed the lowest value which is $3.80 \mathrm{MPa}$. The compressive strength of the concrete samples for 28 day curing period showed increased high strength and also indicates that the sample has reached maturity in providing more strength.

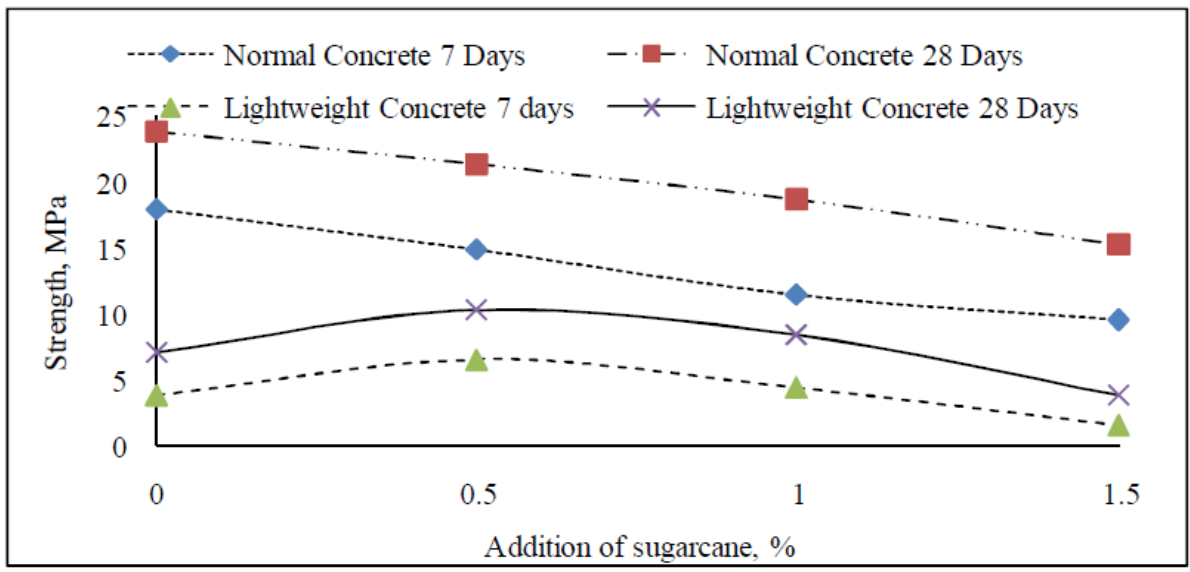

Fig. 4. Compressive Strength of Concrete with Sugarcane Fibre.

\subsection{Tensile strength of concrete}

The control sample of normal concrete containing $0 \%$ sugarcane recorded a reading of 2.10 MPa tensile strength as shown in Fig. 5. For samples containing $0.5 \%$ additive showed higher readings than the control sample that is $2.16 \mathrm{MPa}$ for the curing 28 days. The sample containing $1.0 \%$ sugarcane representing $2.22 \mathrm{MPa}$ is higher than $0.5 \%$. Sample containing $1.5 \%$ sugarcane representing has highest tensile strength for 28 days curing that is 2.29 $\mathrm{MPa}$. For the 28-day tensile the strength, the sample containing $1.5 \%$ sugarcane fiber showed a high increase in tensile strength. This indicates that the sample $1.5 \%$ has reached a stage of maturity in giving more strength and it also possible to increase other properties of concrete like durability and cracking resistance towards concrete.

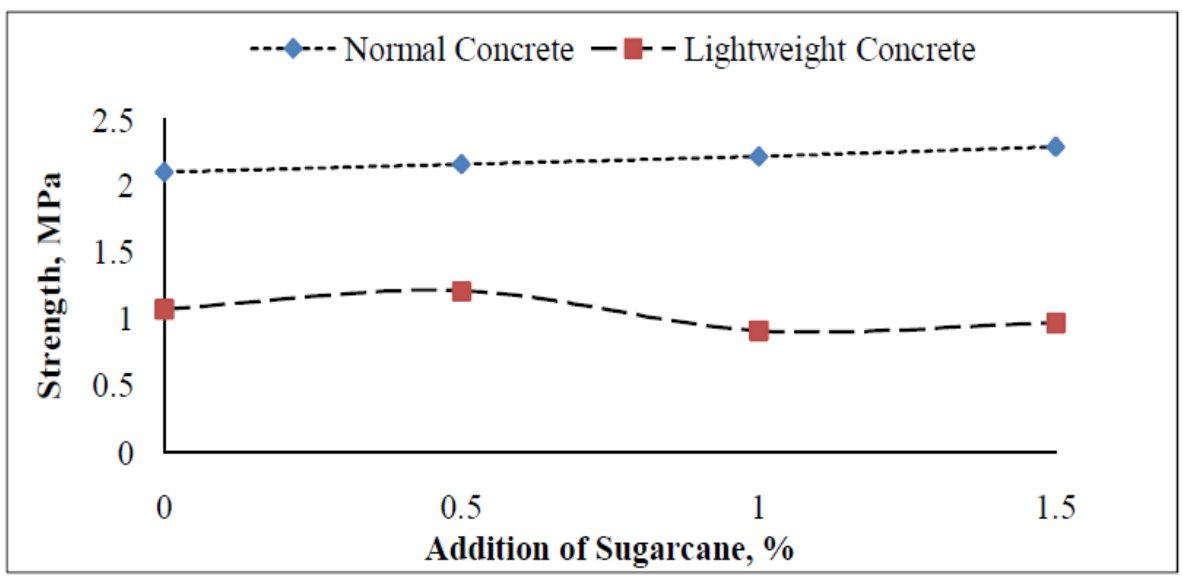

Fig. 5. Tensile strength of the concrete for 28 days. 
Meanwhile, the lightweight concrete for control specimen is $1.07 \mathrm{MPa}$. However, the $0.5 \%$ of addition of sugarcane bagasse gives maximum tensile strength at 28 days as compared to $1.0 \%$ and $1.5 \%$ addition of fiber sugarcane bagasse which was $1.21 \mathrm{MPa}$. Concrete with $1.5 \%$ sugarcane bagasse slightly decreased by the value of $0.97 \mathrm{MPa}$. The lowest value of tensile strength of this experiment was $1.0 \%$ sugarcane bagasse with $0.91 \mathrm{MPa}$. Incorporating of sugarcane bagasse tends to reduce the tensile strength. A decreased of tensile is observed with the increase of fiber proportion. Fig. 5 shows the tensile strength of the concrete for 28 days.

The fiber properties control the strength behavior of concrete that contains fibers. Fibers with higher tensile strength transfer more tensile stress from a cracked zone to the fibers. The tensile strength of fiber used in this research work is significant to create bridge stress between fiber and concrete matrix during tensile test.

\section{Conclusions}

Based on the analysis of data and discussion that has been carried out, it was shown that concrete containing sugarcane fibers in consistent with the properties of ordinary concrete. Compressive strength of the concrete were decreased when the amount of sugarcane fiber increased. The optimum percentage that give the higher compressive strength is $0.5 \%$ either for normal concrete or lightweight concrete and this is not far from the strength of concrete control.Tensile strength of the concrete were increased when the amount of sugarcane fiber increase especially for normal concrete since $1.5 \%$ volume of sugarcane is the highest compared with the tensile strength of concrete control. However, optimum tensile strength of the lightweight with sugarcane fibre is $0.5 \%$. When the sugarcane fibre keep increasing, the tensile strength of the lightweight concrete was reduced.

Physical characteristics of the concrete compressive strength and tensile strength of concrete shows that sugarcane fiber content affects the physical properties of ordinary concrete. The optimum value of sugarcane is $0.5 \%$ percent although they did not affect the compressive strength of concrete but in terms of tensile strength percent sugarcane fiber is still beyond the control of the tensile strength of normal concrete. However, the increment of sugarcane fibre in the lightweight concrete reduce the tensile strength of the lightweight concrete. Overall, volume fiber content of $0.5 \%$ of sugarcane bagasse was the significantly for mix design for normal concrete and lightweight concrete containing sugarcane.

\section{References}

[1] M.S. Frías, E. Villar-Cocina and E. Valencia-Morales, Characterisation of sugar cane straw waste as pozzolanic material for construction: Calcining temperature and kinetic parameters, Waste Management, 27(53), 3-8, (2007)

[2] D. Govindarajan and G. Jayalakshmi, XRD, FTIR and microstructure studies of calcined sugarcane bagasse ash, Advances in Applied Science Research, 2, 544-9 (2011a)

[3] J.M. Irwan, S.K. Faisal, N. Othman and M.H. Wan Ibrahim, Performance of concrete using light waste PET fibre, Advanced Materials Research, 795, 352-335, (2013)

[4] F. Olutoge, O. Ofuyatan, A. Rachael and E. Opaluwa, Strength characteristics of concrete reinforced with sugarcane bagasse fiber, IOSR Journal of Mechanical and Civil Engineering, 12(3), 68-71, (2015)

[5] M.K. Yashwant and BG. Nareshkumar, An experimental study on bagasse ash as replacement for cement in ligthweight concrete, Int. J. of Latest Trends in Engineering and Technology, 3(3), 253-260, (2013) 
[6] V. Srivastava, P. K. Mehta and S. Nath, Natural fiber in cement and concrete matrices. J. of Environment in Nanotechnology, 2(3), 63 - 66, (2013)

[7] G.C. Cordeiro, R.D. Toledo-Filho, L.M. Tavares and E.M.R. Fairbairn, Ultrafine grinding of sugar cane bagasse ash for application as pozzolanic admixture in concrete, Cement Concrete Research. 39,110-5, (2009)

[8] A. Bahurudeen, A.V. Marckson, A. Kishore and M. Santhanam, Development of sugarcane bagasse ash based Portland pozzolana cement and evaluation of compatibility with superplasticizers, Construction Building Materials, 68, 465- 475, (2014)

[9] M. Frías, E. Villar and H. Savastano, Brazilian sugar cane bagasse ashes from the cogeneration industry as active pozzolans for cement manufacture, Cement Concrete Composite, 33, 490-496, (2011)

[10]M. Gesoglu, E. Güneyisi, A.H. Nahhab and H. Yazıcı, The effect of aggregates with high gypsum content on the performance of ultra-high strength concretes and Portland cement mortars, Construction Building Materials, 110, 346-354, (2016)

[11]A.M. Rashad, Metakaolin as cementitious material: history, scours, production and composition - a comprehensive overview, Construction Building Materials, 41(3), 3 $18,(2013)$

[12]EN 12390-3:2000, Design of concrete structures: Testing hardened concrete: Compressive strength for test specimens, British Standard Institution, London, (2000)

[13]EN 12390-6:2000, Design of concrete structures: Testing of hardened concrete: tensile strength test, British standard. British Standard Institution, London, (2000)

[14] S. Shahidan, H.B. Koh, A.M.S. Alansi and L.Y. Loon, Strength development and water permeability of engineered biomass aggregate pervious concrete, MATEC Web Conf., 47, 2-7 (2016)

[15]M. Abdul Rahim, N.M. Ibrahim, Z. Idris, Z.M. Ghazaly, S. Shahidan, N.L. Rahim, L. A. Sofri and N.F. Isa, properties of concrete with different percentage of the rice husk ash (RHA) as partial cement replacement, Material Science Forum, 803, 288 -293 (2014) 